\title{
Training Parents of Children with Intellectual Disabilities: Trends, Issues, and Future Directions
}

\author{
Wendy Machalicek $^{1} \cdot$ Russell Lang $^{2} \cdot$ Tracy Jane Raulston $^{3}$
}

Published online: 9 April 2015

(C) Springer International Publishing Switzerland 2015

\begin{abstract}
This review summarizes selected studies involving education and training programs designed to improve parents' ability to provide research-based support and intervention for their children with intellectual disabilities. First, we highlight stressors and obstacles associated with parenting a child with intellectual disability and note the relative paucity of existing research in light of the increased risk of stress, anxiety, and depression reported for this population. Next, we provide a description of recent trends and issues and attempt to elucidate gaps in the existing literature that warrant additional research effort. Ultimately, this paper highlights the growing need for interventions that include both behavioral and psychosocial components to better address needs in families of children with intellectual disability. Specifically, we conclude that there exists a need for future research on culturally sensitive parent training as well as on potentially efficient group-based parent education programs for families of children with moderate to profound intellectual disability.
\end{abstract}

Keywords Parenting · Intellectual disability .

Developmental disability $\cdot$ Family $\cdot$ Mother $\cdot$ Father .

Family systems

This article is part of the Topical Collection on Intellectual Disability

Wendy Machalicek

wmachali@uoregon.edu

1 Department of Special Education and Clinical Sciences, University of Oregon, 901 E. 18th Ave., Eugene, OR 97403-5253, USA

2 Clinic for Autism Research Evaluation and Support, Texas State University, San Marcos, TX, USA

3 University of Oregon, Eugene, OR, USA

\section{Introduction}

For most families, parenting provides an ongoing source of happiness and joy as well as increased responsibility, anxiety, and stress [1]. There is a great deal of research devoted to typical child developmental stages and trajectories, parenting strategies, and the impact parenting has on family functioning, coping, and well-being (e.g., [2-4]). This large corpus of research focused on typically developing children is regularly summarized and translated from scientific form to a more accessible layperson style written to educate parents on child development and prepare them with home-based strategies for facilitating typical children's language, social, motor, selfhelp, and early academic skills (e.g., [5]). Clearly, raising any child can be a difficult and emotional task for any parent; unfortunately, information pertaining to typical child development and childrearing strategies created for typically developing children may be of limited potential benefit for parents of children with an intellectual or developmental disability (IDD).

Parents of children with an IDD obviously and undeniably experience the same love and joy for their children [6,7], but they also have an increased risk of encountering stressors (e.g., high medical costs), anxiety, and depression $[8,9]$. Increased rates of stress, anxiety, and depression reported in samples of parents of children with IDD are understandable given the unique and emotionally demanding challenges faced by these families. The level of support that a child with IDD requires differs, in part, according to the nature and severity of the IDD, but the majority of children with IDD require care and supports beyond that provided to typically developing children. For example, by definition, children with IDD present with high support needs in adaptive behavior and functional life activities $[10,11]$. Additionally, children with IDD often present with an increased risk of comorbid mental health 
issues including severe and sometimes life-threatening behavior problems such as aggression, self-injurious behavior, and elopement [12-14]. Finally, individuals with profound intellectual and multiple disabilities may present with orthopedic impairment, sensory disabilities, and a range of chronic health issues such as seizure disorders, difficulty maintaining core body temperature, and feeding issues $[15,16]$.

In the context of parenting, even small daily stressors can adversely affect a family's ability to cope [17]. Difficulty coping and adjusting to the lifestyle necessary to meet the needs of a child with IDD can occasion the onset of additional threats to the quality of family life. For example, parents of children with IDD may be at increased risk for relationship discord [18, 19] including increased divorce rates (e.g., [20]). Further, the cost of early intensive intervention services, specialized child care, and the medical bills associated with comorbid conditions, can deplete a family's financial resources (e.g., [21]). Finally, specialized child care can be difficult to obtain for working parents with a child with IDD (e.g., [22]). Therefore, parents of children with IDD are often faced with challenges greater than those faced by parents of typically developing children but have fewer supports and resources (i.e., family support, money, time) available to address those challenges.

Parents of children with significant intellectual disability (i.e., moderate to profound intellectual disability or profound and multiple disability) may benefit from informal (e.g., support groups) and formal (e.g., home-based intervention, functional behavior assessment, group or individualized parent education, respite care, medical device rental) services, and supports to address their child's needs but may also benefit from learning skills to mediate the impact of caring for a child with a significant disability $[23,24]$. Parents have unique influence on their child's acquisition of new skills through their continual and powerful presence in their child's life [25-27]. In addition, parent acquisition of relevant skills (e.g., behavior management strategies) can decrease stressful parent-child interactions during family routines and increase their child's independence (e.g., [28, 29]). Moreover, improving parent optimism and sense of self-efficacy in addressing their child's adaptive behavior needs may improve child and parent outcomes (e.g., [30]). Research involving parents of children with disabilities has demonstrated the effectiveness of parentimplemented interventions to improve a variety of child outcomes as well as improve parent self-efficacy and well-being (e.g., [31]).

Professionals seeking to develop intervention programs for parents of children with significant intellectual disability have a large database of evidence-based practices shown to be effective when used by teachers, researchers, and other professionals to improve adaptive behavior domains and decrease challenging behavior [32-35]. In addition, past reviews of the parent education literature for parents of children with IDD (e.g., autism spectrum disorder [ASD] and other developmental disorders, intellectual disability) are numerous and have included well-designed systematic reviews of interventions [36-41, 42••, 43••, 44]. Unfortunately, few studies included in the aforementioned literature reviews have focused specifically on parents of children with significant intellectual disability.

Due to the unique needs of children with significant intellectual disability, parents of these children have an increased need for supports, educational programming, and interventions to assist them in facilitating and nurturing their child's development, managing the impact of chronic stressors, and buttressing parent and family well-being. Although evidencebased practices for improving outcomes for children with significant intellectual disabilities and for training parents in skill acquisition and behavior management strategies are relatively well-researched, there is nonetheless a need to examine the utility and effectiveness of these strategies when used by parents of children with intellectual disability in family homes and in the community. The purpose of this selective review is to summarize and discuss recent research involving education and training for parents of children with IDD and to identify promising practices for further evaluation with children who experience significant intellectual disability. The remainder of this chapter is organized into three sections: (a) trends and issues, (b) future research and limitations, and (c) conclusion.

\section{Trends and Issues}

This section is organized around the following questions: (a) Who participates in parent education interventions?; (b) what child and parent skills do parent education interventions target?; and (c) what methods are used to train parents?

\section{Who Participates in Parent Education Interventions?}

Although interventions for parents of children with IDD have received some attention in the parent education literature [45-56], it appears that the majority of recent parent education interventions have included parents of children with ASD rather than children with an intellectual disability.

Past reviews of the parent education literature for children with IDD have examined parent education programs implemented by parents of children (a) ages birth to 8 years with any disability [42••], (b) ages 18-60 months with language impairment [43・•], (c) with ASD ranging from ages 1 month to 17 years [36-41, 44, 45], and (d) with intellectual or developmental disability (not ASD) for children ages 1.5 to 17 years [45]. Clearly, past reviews have tended to focus on parents of children with ASD rather than intellectual disability. In addition, to our knowledge, none have critically evaluated the 
literature as it pertains to parents of children with significant intellectual disability (i.e., moderate to profound intellectual disability and/or severe and multiple disability and only one randomized control trial (RCT) has been conducted with children with IDD who engage in serious challenging behavior (e.g., aggression, tantrums, SIB) [6]. Reichow and colleagues (2013) [45] conducted a systematic review of non-specialist psychosocial interventions for children and adolescents with intellectual disability or low-functioning ASD (e.g., autistic disorder, intelligence quotient less than 70) and found that the majority of studies involved children with lowerfunctioning ASD rather than intellectual disability.

The existing literature's focus on supporting parents of children with ASD may present only minimal barriers to professionals selecting practices for families of children with intellectual disability. Diagnostic differences exist between ASD and intellectual disability, but we believe that sufficient overlap exists between the support needs of children with ASD and significant intellectual disability to warrant crossfertilization of intervention strategies. In fact, some researchers have estimated that $50 \%$ of individuals with ASD have comorbid intellectual disability [57].

The bulk of the literature reports mothers as the parent participating as interventionist; this phenomenon continues even in the most recent research despite the fact that older research has documented the positive impact fathers have on their child's development [58-60], social communication [61], and remediation of behavioral excesses for children with developmental disability [62]. Fathers are largely absent in the parenting education literature [63, 64], but our own clinical work with families suggests that fathers are not absent in children's daily lives and many take on a primary caregiver role. While it is true that mothers are often the primary caregiver of children with and without disabilities, the inclusion of mothers alone may not be adequate to address the complex adaptive behavior challenges and support needs presented by children with significant intellectual disabilities. In addition, given the increased stressors placed on caregivers of children with IDD [8], it would seem pertinent to evaluate interventions aimed at improving the self-efficacy of both parents and perhaps also siblings and extended family members. We speculate that this broader family approach could potentially serve to increase continuity of intervention (fidelity of implementation) across caregivers, reduce the demands placed on any one caregiver, and increase positive family interactions that reduce discord between caregivers. However, family-wide training programs involving multiple family members are rare in the research and a comparison of outcomes across studies training one versus multiple family members is not possible in this current review.

Moreover, although there is an increased focus on the perceptions and experiences of parents from diverse cultural backgrounds when designing intervention programs (e.g.,
$[65,66]$, there has been little to no involvement in the parent education literature with parents of children with IDD from diverse cultural and linguistic backgrounds. However, recent research with parents of children, ages 3 to 9 years, with and without intellectual disability, has identified differences in parenting and cultural beliefs for culturally diverse mothers [65, 66] that may influence parent acceptance of existing parent education programs. Numerous reviews of the parent education literature have echoed this concern, e.g., [43••, 44], and it is troubling that little to no research exists in this area.

\section{What Child and Parent Skills Do Parent Education Interventions Target?}

Evidence-based parenting education programs for parents of children with IDD often target the management of conduct disorders, e.g., [38, 40, 46]; functional or social communication, e.g., [41, 43••]; or early intensive applied behavior analysis (EIABA) for young children with ASD, e.g., $[37,39,44]$.

Fewer resources and empirical investigations of parent training to specifically improve child functional life skills (e.g., using task analysis and prompting hierarchies to teach children to make their bed), play and leisure skills [67], selfdetermination [68], feeding problems [49, 69, 70], sleep [71], and toileting [72] are available. Additionally, the majority of these studies include participants with ASD rather than intellectual disability. However, there are some notable exceptions in the research literature. For instance, Fey, Yoder, Warren, and Bredin-Oja (2013) [73] examined dosage-dependent effects of milieu communication teaching (MCT) with 64 children with intellectual disability and communication delay. Children were randomly assigned to receive MCT one or five times each week across the 9-month intervention. Growth was observed across both groups, but surprisingly increased frequency of MCT was only observed when the children demonstrated more diverse object engagement (i.e., children played with nine or more objects during play assessment). Singlecase research design studies have evaluated parentimplemented instruction on functional life skills routines such as hand washing and eating a snack, i.e., [74]. Batu (2014) [74] evaluated the effects of parent-implemented instruction (i.e., simultaneous prompting with activity schedule) following instruction delivered via an audiovisual recording (DVD) on hand washing and eating pudding for three children with moderate intellectual disability.

Additionally, family systems theory posits that parent wellbeing affects the well-being of the child and entire family system [75]. This is supported by an apparent increased interest in interventions addressing parent stress (for a review see [69). Durand and colleagues (2012) [6] offer a unique type of clinic-based intervention package that both teaches parents skills to manage child challenging behavior and to address 
negative self-talk to address complex parent-child interactions and proactively address psychological barriers to treatment adherence by parents. In their randomized clinical trial with 54 parents and their children with a developmental disability who engaged in serious challenging behavior (e.g., self-injury, aggression), the researchers compared the effects of positive behavior support alone to positive behavior support plus the addition of optimism training (adapted from Seligman's 1998 cognitive behavioral optimism training). Participating parents in both groups were selected for having high levels of pessimism prior to intervention. Although both groups were assessed to have less challenging behavior at post-test and decreased parent pessimism, the positive family intervention (PFI; positive behavior support plus the addition of optimism training) resulted in a significantly decreased challenging behavior when compared to the positive behavior support only group. In addition, although intervention did not occur in the family home, behavioral observations indicated a decreased challenging behavior at home as well for both groups. These are important findings for an 8-week clinic-based intervention program conducted with often difficult to treat, pessimistic parents.

\section{What Methods Are Used to Train Parents?}

Behavioral parent training (BPT) involving didactic sessions, role-play and rehearsal, performance feedback, train to criterion is the gold standard of parent training for helping parents to address externalizing behaviors with positive outcomes reported for a wide variety of disabilities including conduct disorders, attention-deficit hyperactivity disorder, and developmental disability [76-78]. Kaminski, Valle, Filene, and Boyle (2008) [78] found that requiring parents to practice new intervention skills with their child and parents' consistent use of these skills are essential and necessary components of BPT. In addition, feedback provided to the parent during practice is an assumed mediator for positive child outcomes [37]. Accordingly, it is not surprising that the majority of parent education studies have used a combination of these components to train parents of children with IDD. Less frequently reported, but promising delivery methods, have included video modeling [79], self-instruction [80], and video teleconferencing [81-84]. These approaches are considered attractive service delivery models because they can be cost efficient (e.g., video models may be provided free online) and/or reduce logistical complications inherent in one-on-one inperson training models (delayed feedback being more easily provided than immediate feedback).

Historically, very little in the way of standardized group parent education curricula have been adapted for use with parents of children with IDD. However, several different research teams have undertaken adaptations of group parent education programs for use with an IDD population and a few have emerged with demonstrated efficacy in improving challenging behavior for children with IDD including ASD and physical disabilities [85-87]. These adapted parenting programs include the Stepping Stones Triple P (SSTP) and the Incredible Years Parent Training Program [85]. For example, the SSTP [88] an individual parenting program developed for families of children with a disability to address behavioral problems, has been evaluated as an adjunct to federally funded early intervention services with 25 young children (below 24 months of age) with a variety of developmental disabilities including global developmental delay ( $65 \%$ of the sample), Down syndrome (three children), low birth weight (nine children), and other genetic or congenital conditions (five children). For the treatment group receiving both early intervention services and the SSTP program, when compared to the control group of 24 children, child behavior problems decreased and were associated with improved parenting styles. Additional RCTs suggest the promise of group SSTP to decrease child challenging behavior and improve parenting skills necessary for raising children with a variety of IDD diagnoses including ASD, Down syndrome, cerebral palsy, and intellectual disability [89].

\section{Future Research and Limitations}

Parents have been included in a number of meaningful ways that have resulted in positive gains for children with IDD. Much of the current literature involving parents of children with IDD has focused on parent-implemented programs to reduce challenging behavior. However, there is a conspicuous gap in the literature where we would expect and hope to find a variety of individual or group-based parent education programs focused on increasing other essential adaptive behavior skills (e.g., functional communication including the use of augmentative and alternative communication $[\mathrm{AAC}]$ devices or systems, self-help skills such as cooking, and functional academic skills such as telling time). In addition, few if any resources have targeted parents of children with severe and profound intellectual and multiple disabilities. The current state of the literature offers several possibilities for improving the external validity (generalizability) of intervention research conducted with parents of children with intellectual disability.

First, there is the need to develop programs that address the wide range of needs for children with IDD including severe to profound intellectual disabilities and multiple disabilities. One solution to the lack of research representing this population is to extend the research findings of studies focused on utilizing strategies found effective to train and support caregivers of children with less significant disabilities and examine those strategies with parents of children with significant intellectual disabilities to evaluate contextual fit of existing programs. Prevention and problem-based group parent education for 
parents of children with significant disability should not only aim to decrease child challenging behavior, but it should also seek to establish evidence-based strategies to support parents in acquiring skills to support their child's acquisition of ageappropriate adaptive behaviors such as functional life and selfhelp skills, the use of AAC devices and systems to increase functional communication at home and in the community, and in areas identified by parents as important (e.g., making friends). As the context in educational settings for children with intellectual disabilities continues to shift towards academic interventions, in the USA as a result of educational legislation such as the 2001 No Child Left Behind Act (NCLB) and the 2004 Individuals with Disabilities Education Improvement Act (IDEIA) [90, 91], parents may be increasingly tasked with supporting their child's development of functional life skills.

Secondly, of particular interest is the individualization of parent education programs to contextually fit the family and yield optimal benefits with the smallest dose possible [92, 93]. Fey and colleagues (2013) [73] have used the conceptual framework of dosage introduced by Warren in 2007 and growth curve modeling to examine dosagedependent effects of parent implemented communication interventions. Future research should examine the dosagedependent effects of varying amounts and quality (e.g., varying treatment fidelity) of evidence-based intervention to address both parent and child desired outcomes. Systematic research on dosage will better inform our efforts to develop ecologically valid and effective parent education interventions for parents of children with IDD who often present with complex intervention needs.

Third, future research efforts must build on recent advances in knowledge regarding parental stress and well-being. Type of child disability [94], a strong social support system and selfefficacy [18, 95-97], positive parent perception of stressors $[17,98]$, and coping skills $[99,100]$ have all been shown to effectively mediate parental stress. Future research should evaluate the additive nature of interventions targeting potentially malleable variables (e.g., social support network, socioeconomic status) for families of children with significant intellectual disability. In addition, researchers should further evaluate combined intervention programs that use (a) evidence-based interventions to decrease parent stress and depression and improve mental health such as mindfulness based or cognitive behavioral strategies for stress reduction [101, 102] alongside (b) applied behavior analytic interventions to improve child adaptive behavior skills and decrease challenging behavior. Psychological acceptance and mindfulness have been shown to mediate the impact of challenging behavior on parent distress for parents of children with ASD [103]. In addition, it is important for researchers to consider that parent stress continues into a child's adolescence, especially when the child with IDD engages in challenging behavior [100]. Fortunately, if parents have coping skills such as active coping/planning, positive reinterpretation/growth, and behavioral/mental disengagement, the effects of stressful parent-child interactions can be minimized [100]. Early intervention efforts should focus on building parents' repertoire of coping skills to potentially improve long-term outcomes, as the child grows older.

Fourth, to best meet the needs of families of children with IDD from diverse cultural, linguistic, and socioeconomic backgrounds, researchers must hasten their efforts to increase participation by diverse parent and child participants. By 2060, there will be no majority racial/ethnic group [104]. Currently, the vast majority of parent education programs have been empirically evaluated with middle-class families [41]. A multipronged approach to increasing participant diversity in research as discussed by public health scholars, e.g., [105] may support researchers in achieving this goal. For example, Yancey and colleagues suggest among other considerations that (a) journals establish standards for reporting the race/ethnicity, and gender of participants. Parenting intervention studies should also be encouraged to report the roles (e.g., mother, father) of participating parents and any variables potentially mediating the success of the intervention; (b) academics and researchers commit resources to successfully compete for federal doctoral leadership grants and training consortiums focusing on the preparation of Ph.D.-level scholars with expertise in recruitment, retention, and engagement of families from diverse backgrounds; and (c) develop formal and ongoing relationships with local agencies that serve diverse populations. Researchers working with parents of children with IDD may wish to also engage parent support groups and local educational authorities in ongoing recruitment efforts.

Finally, researchers should continue to concentrate on improving the experimental rigor and expanding the external validity of the literature base where possible. A number of researchers have suggested a need for larger sample sizes to evaluate the effectiveness of parent education programs, e.g., [37]. Similarly, to contribute to the evidence base for parent intervention programs for parents of children with significant intellectual disability, we suggest the use of experimentally rigorous single-case research methodology. Single-case research methodology is especially well suited for use with this population due to the low-incidence nature of significant intellectual and multiple disability, which results in difficulty randomly assigning families, and matching participants by characteristics, to treatment and control groups. Historically, this methodology has been widely utilized with lowincidence populations in educational and community settings [106, 107], and there is growing recognition of the validity of single-case methodology by federal funding agencies [108]. 


\section{Conclusion}

We have provided a brief and selective summary of the evidence supporting parent education and intervention programs for parents of children with significant intellectual disabilities and the numerous gaps in the literature warranting future research. We call for future research on individual and groupbased parent education programs involving parents of children with intellectual disabilities and the development of interventions that include both behavioral and psychosocial components to better address child and parent support needs.

\section{Compliance with Ethics Guidelines}

Conflict of Interest Wendy Machalicek, Russell Lang, and Tracy Jane Raulston declare that they have no conflict of interest.

Human and Animal Rights and Informed Consent This article does not contain any studies with human or animal subjects performed by any of the authors.

\section{References}

Papers of particular interest, published recently, have been highlighted as:

•• Of major importance

1. Raphael JL, Zhang Y, Liu H, Giardino AP. Parenting stress in US families: implications for pediatric healthcare utilization. Child Care Health Dev. 2009;36:216-24.

2. Cappa KA, Begle AM, Conger JC, Dumas JE, Conger AJ. Bidirectional relationships between parenting stress and child coping competence: findings from the Pace Study. J Child Fam Stud. 2011;20:334-42.

3. Deater-Deckard K. Parenting stress and child adjustment: some old hypotheses and new questions. Clin Psychol: Sci Pract. 1998;5:314-32.

4. Podolski C, Nigg JT. Parent stress and coping in relation to child ADHD severity and associated child disruptive behavior problems. J Clin Child Psychol. 2001;30:503-13.

5. Murkoff H, Mazel S. What to expect the first year. New York: Workman Publishing; 2014.

6. Durand VM, Hieneman M, Clarke S, Wang M, Rinaldi ML. Positive family intervention for severe challenging behavior I: a multisite randomized clinical trial. J Posit Behav Interv. 2012;15: 133-43.

7. Scallan S, Senior J, Reilly C. William syndrome: daily challenges and positive impact on the family. J Appl Res Intellect Disabil. 2011;24:181-8.

8. Baker BL, Blacher J, Crnic KA, Edelbrock C. Behavior problems and parenting stress in families of three-year-old children with and without developmental delays. Am J Ment Retard. 2002;107:433-44.

9. Singer GHS. Meta-analysis of comparative studies of depression in mothers of children with and without developmental disabilities. Am J Ment Retard. 2006;111:155-69.
10. Harries J, Guscia R, Nettelbeck T, Kirby N. Impact of additional disabilities on adaptive behavior and support profiles for people with intellectual disabilities. Am J Intellect Dev Disabil. 2009;114: 137-253.

11. Schalock RL, Borthwick-Duffy SA, Bradley VJ, Buntinx WH, Coulter DL, Craig EM, et al. Intellectual disability: definition, classification, and systems of supports. Washington, DC: American Association on Intellectual and Developmental Disabilities; 2010.

12. Baker BL, McIntyre LL, Blacher K, Crnic K, Edelbrock C, Low C. Pre-school children with and without developmental delay: behaviour problems and parenting stress over time. J Intellect Disabil Res. 2003;47:217-30.

13. Emerson E, Robertson J, Wood J. Emotional and behavioural needs of children and adolescents with intellectual disabilities in an urban conurbation. J Intellect Disabil Res. 2005;49:16-24.

14. Lang R, Sigafoos J, van der Meer L, O'Reilly MF, Lancioni GE, Didden R. Early signs and early behavioral intervention of challenging behavior. In: Hastings R, Rojahn J, editors. International Review of Research in Developmental Disability, 44. London: Elsevier Inc. Academic Press; 2013. p. 1-35.

15. Kapell D, Nightingale B, Rodriguez A, Lee JH, Zigman WB, Schupf N. Prevalence of chronic medical conditions in adults with mental retardation: comparison with the general population. Ment Retard. 1998;36:269-79.

16. Orelove FP, Sobsey D, Silberman R. Educating children with multiple disabilities: a transdisciplinary approach. 4th ed. Baltimore: Paul H Brookes Publishing Co; 2004.

17. Crnic KA, Greenberg MT. Minor parenting stresses with young children. Child Dev. 1990;61:1628-37.

18. Floyd FJ, Zmich DE. Marriage and the parenting partnership: perceptions and interactions of parents with mentally retarded and typically developing children. Child Dev. 1991;62:1434-48.

19. Kersh J, Hedvat TT, Hauser-Cram P, Warfield ME. The contribution of marital quality to the wellbeing of parents of children with developmental disabilities. J Intellect Disabil Res. 2006;50:883-93.

20. Hartley SL, Barker ET, Mailick Seltzer M, Floyd F, Greenberg J, Orsmond G. The relative risk and timing of divorce in families of children with an autism spectrum disorder. J Fam Psychol. 2010;24:449-57.

21. Lan-Ping L, Chiung-Ying K, Shang-Wei H, Tzong-Nan L, ChaiIm L, Jia-Lin W, et al. Outpatient visits and expenditures for children and adolescents diagnosed with autism spectrum disorders and co-occurring intellectual disability: an analysis of the national health insurance claims data. Res Autism Spectr Disord. 2013;7: 1625-30.

22. McConkey R, Kelly F, Craig S. Access to respite breaks for families who have a relative with intellectual disabilities: a national survey. J Adv Nurs. 2011;67:1349-57.

23. Bailey Jr D. Evaluating parent involvement and family support in early intervention and preschool program. J Early Interv. 2001;24:1-14.

24. Machalicek W, Didden R, Lang R, Green V, Lequia J, Sigafoos J, et al. Parent and sibling interventions. In: Sturmey P, Tarbox J, Dixon D, Matson JL, editors. Handbook of early intervention and autism spectrum disorders. New York: Springer; 2014.

25. Dunst C, Bruder M, Trivette C, Hamby D, Raab M, McLean M. Characteristics and consequences of everyday natural learning opportunities. Top Early Child Spec Educ. 2001;21:68-93.

26. Ingersol B, Gergans S. The effects of a parent-implemented imitation intervention on spontaneous imitation skills in young children with autism. Res Dev Disabil. 2007;28:163-75.

27. Kashinath S, Woods J, Goldstein H. Enhancing generalized teaching strategy use in daily routines by parents of children with autism. J Speech Lang Hear Res. 2006;49:466-85. 
28. Buschbacher P, Fox L, Clarke S. Recapturing desired family routines: a parent-professional behavioral collaboration. Res Pract Persons Sev Disabil. 2004;29:25-39.

29. Clarke S, Dunlap G, Vaughn B. Family-centered, assessmentbased intervention to improve behavior during an early morning routine. J Posit Behav Interv. 1999;1:235-41.

30. Durand VM. Optimistic parenting. Hope and help for you and your challenging child. Baltimore: Paul H. Brookes; 2011.

31. Dunst C, Hamby DW, Brookfield J. Modeling the effects of early childhood intervention variables on parent and family well-being. J Appl Quant Methods. 2007;2:268-88.

32. Nietupski J, Hamre-Nietupski S, Curtin S, Shrikanth K. A review of curricular research in severe disabilities from 1976 to 1995 in six selected journals. J Spec Educ. 1997;31:36-55.

33. Shurr J, Bouck EC. Research on curriculum for students with moderate and severe intellectual disability: a systematic review. Educ Train Autism Dev Disabil. 2013;48:76-87.

34. Snell ME, Brown F. Instruction of students with severe disabilities. 6th ed. Upper Saddle River: Pearson Education, Inc; 2006.

35. Westling DL, Fox L. Teaching students with severe disabilities. 3rd ed. Upper Saddle River: Pearson Education, Inc; 2004.

36. Lang R, Machalicek W, Rispoli MJ, Regester A. Training parents to implement communication interventions for children with autism spectrum disorders: a systematic review of training procedures. Evid Based Commun Assess Interv. 2009;3:174-90.

37. Diggle T, McConachie HR, Randle VRL. Parent-mediated early intervention for young children with autism spectrum disorder. Cochrane Database Syst Rev. 2002, Issue 2. Art. No.: CD003496.

38. Brookman-Frazee L, Stahmer A, Baker-Ericzén M, Tsai K. Parenting interventions for children with autism spectrum and disruptive behavior disorders: opportunities for cross-fertilization. Clin Child Fam Psychol Rev. 2006;9(3-4):181-200.

39. McConachie H, Diggle T. Parent implemented early intervention for young children with autism spectrum disorder: a systematic review. J Eval Clin Pract. 2006;13:120-9.

40. Hastings R, Robertson J, Yasamy M. Interventions for children with pervasive developmental disorders in low and middle income countries. J Appl Res Intellect Disabil. 2012;25(2):119-34.

41. Meadan H, Ostrosky M, Zaghlawan H, Yu S. Promoting the social and communicative behavior of young children with autism spectrum disorders: a review of parent-implemented intervention studies. Top Early Child Spec Educ. 2009;29:90-104.

42.• Barton EE, Fettig A. Parent-implemented interventions for young children with disabilities. J Early Interv. 2013;35:194-219.

Provides a systematic, well-designed review of interventions delivered by parents of children, ages birth to 8 years, with any disability. Most parent education interventions used performance feedback to increase parent use of targeted skills.

43.•- Roberts M, Kaiser A. The effectiveness of parent-implemented language interventions: a meta-analysis. Am J Speech Lang Pathol. 2011;20:180-99. A systematic, well-designed metaanalysis of parent-implemented communication interventions for children, ages 18 to 60 months, with language impairments. Significant effect sizes were reported and ranged from -0.15 to 0.82 suggesting parent-implemented communication intervention is an effective strategy for improving child outcomes.

44. Strauss K, Mancini F, Fava L. Parent inclusion in early intensive behavior interventions for young children with ASD: a synthesis of meta-analyses from 2009 to 2011. Res DD. 2013;34:2967-85.

45. Reichow B, Servili C, Yasamy MT, Barbui C, Saxena S. Nonspecialist psychosocial interventions for children and adolescents with intellectual disability or lower-functioning autism spectrum disorders: a systematic review. Public Libr Sci. 2013;10:1-27.
46. Gavida-Payne S, Hudson A. Behavioral supports for parents of children with an intellectual disability and problem behaviors: an overview of the literature. J Intellect Dev Disabil. 2002;27:31-55.

47. Hudson A, Matthews J, Gavidia-Payne S, Cameron C, Mildon R, Radler G, et al. Evaluation of an intervention system for parents of children with intellectual disability and challenging behaviour. J Intellect Disabil Res. 2003;47:238-49.

48. Hudson A, Cameron C, Matthews J. The wide-scale implementation of a support program for parents of children with an intellectual disability and difficult behaviour. J Intellect Dev Disabil. 2008;33:117-26.

49. Luiselli J. Oral feeding treatment of children with chronic food refusal and multiple disabilities. Am J Ment Retard. 1994;98:646-55.

50. Russell PSS, John JK, Lakshmanan J, Russell S, Lakshmidevi KM. Family intervention and acquisition of adaptive behaviour among intellectually disabled children. J Learn Disabil. 2004;8: 383-95.

51. Schultz C, Schultz N, Bruce E. Psychoeducational support for parents of children with intellectual disability: an outcome study. Int J Disabil Dev Educ. 1993;40:205-16.

52. Shapiro CJ, Kilburn J, Hardin JW. Prevention of behavior problems in a selected population: Stepping Stones Triple P for parents of young children with disabilities. Res Dev Disabil. 2014;35: 2958-75.

53. Singer G, Irvin L, Hawkins N. Stress management training for parents of children with severe handicaps. Ment Retard. 1988;26:269-77.

54. Singer G, Irvin L, Irvine B. Evaluation of community-based support services for families of persons with developmental disabilities. J Assoc Persons Sev Handicap. 1989;14:312-23.

55. Yoder P, Warren S. Effects of prelinguistic milieu teaching and parent responsivity education on dyads involving children with intellectual disabilities. J Speech Lang Hear Res. 2002;45:1158-74.

56. Zingale M, Belfiore G, Mongelli V, Trubia G, Buono S. Organization of a family training service pertaining to intellectual disabilities. J Policy Pract Intellect Disabil. 2008;5:69-72.

57. Totsika V, Hastings R, Emerson E, Lancaster G, Berridge DA. Population-based investigation of behavioral and emotional problems and maternal mental health: associations with autism spectrum disorder and intellectual disability. J Child Psychol Psychiatry. 2011;52:91-9.

58. Carr A. The inclusion of fathers in family therapy: a research based perspective. Contemp Fam Ther. 1998;20:371-83.

59. Elder JH, Valcante G, Won D, Zylis R. Effects of in-home training for culturally diverse fathers of children with autism. Issues Ment Health Nurs. 2003;24:273-95.

60. Lamb ME. The history of research on father involvement. Marriage Fam Rev. 2000;29:23-42.

61. Seung HK, Ashwell S, Elder JH, Valcante G. Verbal communication outcomes in children with autism after in home father training. J Intellect Disabil Res. 2006;50:139-50.

62. Bagner DM. Father's role in parent training for children with developmental delay. J Fam Psychol. 2013;27:650-7.

63. Budd KS, O'Brien TP. Father involvement in behavioral parent training: an area in need of research. Behav Ther. 1982;5:85-9.

64. Coplin JW, Houts AC. Father involvement in parent training for oppositional child behavior. Child Family Behav Ther. 1991;13: 29-51.

65. Blacher J, Begum GF, Marcoulides GA, Baker BL. Longitudinal perspectives of child positive impact on families: relationship to disability and culture. Am J Intellect Dev Disabil. 2013;118:141-55. 
66. Blacher J, McIntyre LL. Syndrome specificity and behavioural disorders in young adults with intellectual disability: cultural differences in family impact. J Intellect Disabil Res. 2006;50:184-98.

67. Keen D, Rodger S, Doussin K, Braithwaite M. A pilot study of the effects of a social-pragmatic intervention on the communication and symbolic play of children with autism. Autism. 2007;11:63-71.

68. Carter EW, Lane KL, Cooney M, Weir K, Moss CK, Machalicek W. Self-determination among transition-age youth with autism or intellectual disability: parent perspectives. Res Pract Persons Sev Disabil. 2013;38:129-38.

69. Gentry J, Luiselli J. Treating a child's selective eating through parent implemented feeding intervention in the home setting. $\mathrm{J}$ Dev Phys Disabil. 2008;20:63-70.

70. Ledford J, Gast D. Feeding problems in children with autism spectrum disorders: a review. Focus Autism Other Dev Disabil. 2006;21:153-66.

71. Weiskop S, Matthews J, Richdale A. Treatment of sleep problems in a 5-year-old boy with autism using behavioural principles. Autism. 2001;5:209-21.

72. Kroeger K, Sorensen R. A parent training model for toilet training children with autism. J Intellect Disabil Res. 2010;54:556-67.

73. Fey ME, Yoder PJ, Warren SF, Bredin-Oja S. Is more better? Milieu communication teaching in toddlers with intellectual disabilities. J Speech Lang Hear Res. 2013;58:679-93.

74. Batu S. Effects of teaching simultaneous prompting through visual supports to parents of children with developmental disabilities. Educ Train Autism Dev Disabil. 2014;49:505-16.

75. Minuchin P. Families and individual development: provocations from the field of family therapy. Child Dev Spec Issue: Fam Dev. 1985;56:289-302.

76. Kazdin AE, Weisz JR. Identifying and developing empirically supported child and adolescent treatments. J Couns Clin Psychol. 1998;66:19-36.

77. Shaffer A, Kotchick BA, Dorsey S, Forehand R. Parenting antisocial children and adolescents. In: Hoghughi M, Long N, editors. Handbook of parenting. London: Sage; 2004. p. 256-75.

78. Kaminski JW, Valle LA, Filene JH, Boyle CL. A meta-analytic review of components associated with parent training program effectiveness. J Abnorm Child Psychol. 2008;36:567-89.

79. Van Balkom H, Verhoeven L, Van Weerdenburg M, Stoep J. Effects of parent-based video home training in children with developmental language delay. Child Lang Teach Ther. 2010;26: 221-37

80. Nefdt N, Koegel R, Singer G, Gerber M. The use of a self directed learning program to provide introductory training in pivotal response treatment to parents of children with autism. J Posit Behav Interv. 2010;12:23-32.

81. McDuffie A, Machalicek W, Oakes A, Haebig E, Weismer SE, Abbeduto L. Distance video-teleconferencing in early intervention: pilot study of a naturalistic parent-implemented language intervention. Top Early Child Spec Educ. 2013;33:172-85.

82. Wacker DP, Lee JF, Dalmau YCP, Kopelman TG, Lindgren SD, Kuhle J, et al. Conducting functional analyses of problem behavior via telehealth. J Appl Behav Anal. 2013;46:31-46.

83. Wacker DP, Lee JF, Dalmau YCP, Kopelman TG, Lindgren SD, Kuhle J, et al. Conducting functional communication training via telehealth to reduce the problem behavior of young children with autism. J Dev Phys Disabil. 2013;25:35-48.

84. Suess AN, Romani PW, Wacker DP, Dyson SM, Kuhle JL, Lee JF, et al. Evaluating the treatment fidelity of parents who conduct inhome functional communication training with coaching via telehealth. J Behav Educ. 2014;23:34-59.

85. McIntyre LL. Parenting training for young children with developmental disabilities: randomized controlled trial. Am J Ment Retard. 2008;113:356-68.
86. Roberts C, Mazzucchelli T, Studman L, Sanders M. Behavioural family intervention for children with developmental disabilities and behavioural problems. J Clin Child Adolesc Psychol. 2006;35:180-93.

87. Whittingham K, Sofronoff K, Sheffield J, Sanders MR. Stepping Stones Triple P: an RCT of a parenting program with parents of a child diagnosed with an autism spectrum disorder. J Abnorm Child Psychol. 2009;37:469-80.

88. Sanders MR, Mazzucchelli TG, Studman LJ. Practitioner's manual for Standard Stepping Stones Triple P. Brisbane: Triple P International; 2003.

89. Roux G, Sofronoff K, Sanders M. A randomized controlled trial of group Stepping Stones Triple P: a mixed-disability trial. Fam Process. 2013;52:411-24.

90. Ayres KM, Douglas KH, Lowrey KA, Sievers C. I can identify Saturn but I can't brush my teeth: what happens when the curricular focus for students with severe disabilities shifts. Educ Train Autism Dev Disabil. 2011;46:11-21.

91. Browder DM, Cooper-Duffy K. Evidence-based practices for students with severe disabilities and the requirement for accountability in "No Child Left Behind". J Spec Educ. 2003;37:157-63.

92. Eldevik S, Eikeseth S, Jahr E, Smith T. Effects of low-intensity behavioral treatment for children with autism and mental retardation. J Autism Dev Disord. 2006;36:211-24.

93. Vismara LA, Colombi C, Rogers SJ. Can one hour per week of therapy lead to lasting changes in young children with autism? Autism. 2009;13:93-115.

94. Eisenhower AS, Baker BL, Blacher J. Preschool children with intellectual disability: syndrome specificity, behaviour problems, and maternal wellbeing. J Intellect Disabil Res. 2005;49:657-71.

95. Coleman P, Karraker K. Self-efficacy and parenting quality: findings and future applications. Dev Rev. 1998;18:47-85.

96. Green SE. 'We're tired, not sad': benefits and burdens of mothering a child with a disability. Soc Sci Med. 2007;64:150-63.

97. Raikes H, Thompson R. Efficacy and social support as predictors of parenting stress among families in poverty. Ment Health J. 2005;26:177-90.

98. Trute B, Benzies KM, Worthington C, Reddon JR, Moore M. Accentuate the positive to mitigate the negative: mother psychological coping resources and family adjustment in childhood disability. J Intellect Dev Disabil. 2010;35:36-43.

99. Lee GK. Parents of children with high functioning autism: how well do they cope and adjust? J Dev Phys Disabil. 2009;21:93-114.

100. Woodman AC, Hauser-Cram P. The role of coping strategies in predicting change in parenting efficacy and depressive symptoms among mothers of adolescents with developmental disabilities. J Intellect Disabil Res. 2013;57:513-30.

101. Hastings RP, Beck A. Practitioner review: stress intervention for parents of children with intellectual disabilities. J Child Psychol Psychiatry. 2004;45:1338-49.

102. Bazzano A, Wolfe C, Zylowska L, Wang S, Schuster E, Barrett C, et al. Mindfulness based stress reduction (MBSR) for parents and caregivers of individuals with developmental disabilities: a community-based approach. J Child Fam Stud. 2015;24:298-308.

103. Jones L, Hastings RP, Totsik V, Keane L, Rhule N. Child behavior problems and parental well-being in families of children with autism: the mediating role of mindfulness and acceptance. Am J Intellect Dev Disabil. 2014;119:171-85.

104. United States Census Bureau. Resident population estimates of the United States by sex, race, and Hispanic origin. 2014 national population projects from July 1, 2014 to July 1, 2060. Retrieved from http://www.census.gov/population/projections/data/national/ 2014.html March 19, 2015.

105. Yancey AK, Ortega AN, Kumanyika SK. Effective recruitement and retention of minority research participants. Annu Rev Public Health. 2006;27:1-28. 
106. Gast DL, Ledford JR. Single case research methodology applications in special education and behavioral sciences. 2nd ed. New York: Routledge; 2014.

107. Kennedy $\mathrm{CH}$. Single-case designs for educational research. Boston: Allyn and Bacon; 2005.
108. Kratochwill TR, Hitchcock J, Horner RH, Levin JR, Odom SL, Rindskopf DM, Shadish WR. Single-case designs technical documentation. 2011; Retrieved from What Works Clearinghouse website: http://ies.ed.gov/ncee/wwc/pdf/wwc_scd.pdfY. 